\title{
SOBRE LIVROS E LEITORES: DESENVOLVIMENTO DE INSTRUMENTO PARA APURAÇÃO DE SIGNIFICADOS PERTINENTES À ATIVIDADE DE LEITURA
}

\author{
Letícia Lima de Barros (discente)/UFPE \\ Guilherme Ranoya Seixas Lins (orientador)/UFPE
}

\section{RESUMO}

O estudo pretende apresentar um instrumento destinado à avaliação da relação entre sujeitos e leitura em livros físicos, construído a partir do referencial oferecido pela tríade hierárquica da atividade de Leontiev (1981) e pelo diagrama de 2a geração do Sistema de Atividade de Engeström (1987), na intenção de identificar significados particulares aos sujeitos observados ao longo da atividade de leitura. Esse instrumento assume a forma de questões direcionadas a uma entrevista estruturada, aplicada a dois grupos de sujeitos em momentos distintos, com tratamento das informações levantadas realizado a partir das considerações de Baptista (2019). Através desse estudo piloto, identificou-se que a ferramenta desenvolvida tem se mostrado propícia para a captura do ponto visado pela pesquisa, porém demanda mais testes para seu refino. Tenciona-se aprimorar a ferramenta elaborada para posterior emprego em parte da pesquisa realizada no trabalho de dissertação.

Palavras-chave: Teoria da Atividade, design editorial, leitura.

\section{Mediação, atividade, ações e operações na Teoria da Atividade}

A partir da conceituação proposta pela Teoria da Atividade (LEONTIEV, 1978), alinhada aos estudos de Lev Vygotsky e Alexander Luria, tem-se a caracterização das atividades humanas como mediadas por artefatos - materiais ou psicológicos - e direcionadas a objetivos específicos. O entendimento desses objetivos colabora na compreensão dos sujeitos e de suas experiências vinculadas aos artefatos em questão. A partir disso, o trabalho pretende propor uma ferramenta para coleta de informações acerca da experiência de leitores com livros físicos. A construção dessa ferramenta tenciona viabilizar a identificação de significados particulares ao sujeito decorrentes de ações presentes ao longo da leitura, considerando o motivo da realização da atividade como o elemento que "cria um arcabouço psicológico para o indivíduo e torna as ações, aparentemente desconectadas do objetivo, cheias de significado" (CAMPELLO, 2009, p. 191), compreendendo-o, assim, como vinculado à realização da tarefa e produtor do significado das ações efetuadas.

O conceito de mediação é um dos postulados de Vygotsky, conforme apontado por Rego (2011), entendendo-o como presente em toda atividade humana e realizado a partir de instrumentos técnicos e sistemas de signos. Compreende-se, assim, que a interação do indivíduo com o seu redor dá-se de modo indireto, considerando o papel das ferramentas no auxílio das ações efetuadas pelos 
sujeitos. Tais signos e instrumentos são desenvolvidos sócio historicamente e implicam em mudanças culturais; a linguagem, por exemplo, configura-se como mediadora por conter conceituações generalizadas e produzidas por humanos (VYGOTSKY, 1991; REGO, 2011).

A atividade humana, por sua vez, é resultante da relação do indivíduo com o espaço circundante e motivada por uma necessidade. Pode ser compreendida como os processos caracterizados pelo objetivo a que se destinam, sendo esse objetivo o fator que conduz o sujeito à feitura da atividade. Assim sendo, a atividade, em sua gênese, não ocorre sem a figura de um motivo intrinsecamente conectado a ela, pois seu propósito é o que a origina. Esse motivo também coordena certas experiências psíquicas, como emoções e sentimentos, ligados ao direcionamento da atividade que integram. As ações, assim, são os componentes da atividade que a traduzem para a realidade (LEONTIEV, 2010, 1981).

Assim como a noção de motivo se conecta à atividade, a ideia de meta, algo mais imediato, vinculase à ação. A satisfação da necessidade não seria, então, realizada através do resultado gerado pela ação, mas pelo conjunto maior de ações em somatória, que, por integrarem a atividade, conseguiriam produzi-la. O motivo da ação não se equipara a seu objetivo, mas situa-se dentro da atividade que integra. Quando uma leitura é feita por um estudante apenas com o intuito de aprovação em uma avaliação, e não para a compreensão do conteúdo ali tratado, o processo incorpora a forma de ação, pois o ato se realiza em função da necessidade de aprovação (LEONTIEV, 2010, 1981; CAMPELLO, 2009). As ações também possuem seu aspecto operacional, relacionado às circunstâncias sob as quais se realiza.

As operações relatam sobre como um ato pode ser executado. Quando há, como objetivo, decorar versos, a ação consistirá na memorização deles, porém as maneiras de recordar as palavras podem ser diferentes (escrever, repetir); uma mesma ação pode ser composta por distintas operações. Leontiev $(1981,1978)$ também pontua que operações estão no círculo dos processos inconscientes e ações encontram-se dentro de processos conscientes, mas as primeiras, através da internalização, passaram de conscientes a inconscientes.

Assim, o fluxo geral da atividade contém as unidades: 1) atividade, direcionada a seu motivo; 2) ações, processos conectados a seus objetivos conscientes e 3) operações, que dependem das condições nas quais um objetivo concreto será alcançado. (LEONTIEV, 1981). O quadro abaixo, de Campello (2009), demonstra tais níveis do sistema de atividade: 
NÍVEL TATOR DE ORIENTAÇÃO

Atividade
Motivo

Metas
N ATUREZA

Coletiva e consciente

Individual e consciente

Operação

Figura 01: Tríade hierárquica da atividade. Fonte: Adaptado de Campello (2009).

\section{Modelos do Sistema de Atividade de Engeström}

Partindo do conceito de mediação trazido por Vygostsky, Engeström (1987) apresenta, através de diagramas, os elementos integrantes da atividade e a relação entre seus componentes. O diagrama de segunda geração trabalha a relação contextual entre indivíduo e coletivo, incluindo os elementos: indivíduo, instrumento, objeto (ou objetivo), regras, comunidade e divisão do trabalho. A questão central da atividade é o objetivo:

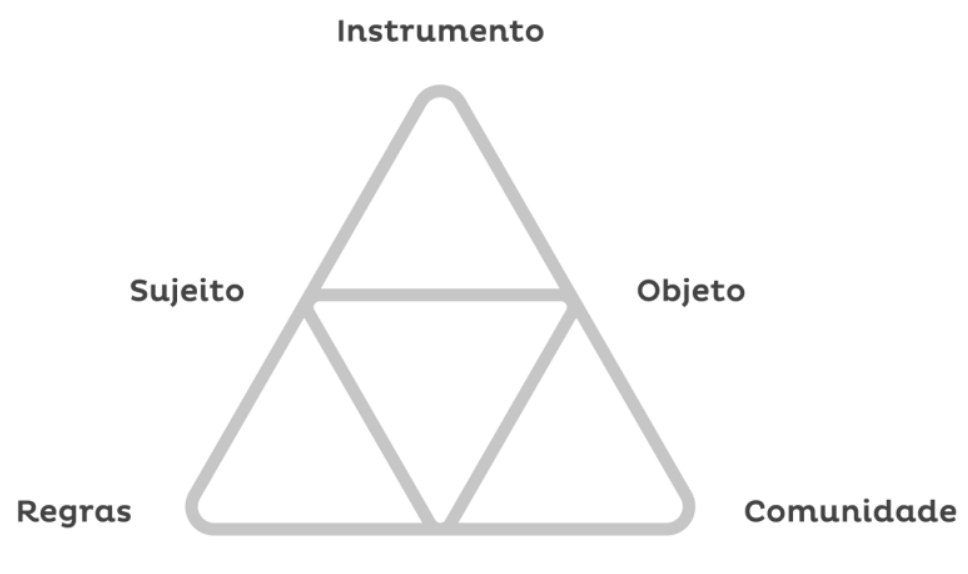

Divisão do trabalho

Figura 02: Diagrama de segunda geração de Engeström, contendo elementos relacionados ao aspecto social da atividade. Fonte: Adaptado de Engeström (1987).

As regras são convenções sociais implícita ou explicitamente adotadas (organizacionais, interpessoais); a divisão do trabalho diz respeito à organização de uma comunidade, e a própria comunidade consiste no conjunto de sujeitos que compartilham o mesmo objetivo. Os recursos de mediação - instrumento, regras e divisão do trabalho - relacionam-se ao contexto em que se encontram inseridos (ENGESTRÖM, 1987; BAPTISTA, 2019). 
Aqui, considerou-se a estrutura hierárquica da atividade e os componentes do sistema de atividade para o desenvolvimento da ferramenta de análise, cuja constituição encontra-se descrita a seguir.

\section{Desenvolvimento da ferramenta}

Para construção das questões empregadas na entrevista, utilizou-se da estrutura hierárquica de Leontiev (1981), compreendendo a atividade de leitura decomposta em ações e operações. A fragmentação em unidades menores favoreceu a visualização de similaridades entre certos blocos de ações e operações, permitindo o agrupamento delas em eixos temáticos, que conduziram à formação das questões aplicadas junto aos respondentes, bem como à intenção por trás de cada pergunta e possíveis direcionamentos das respostas desencadeadas por ela. Dessa forma, encontrouse, através da hierarquia, assuntos passíveis de exploração no decorrer das entrevistas.

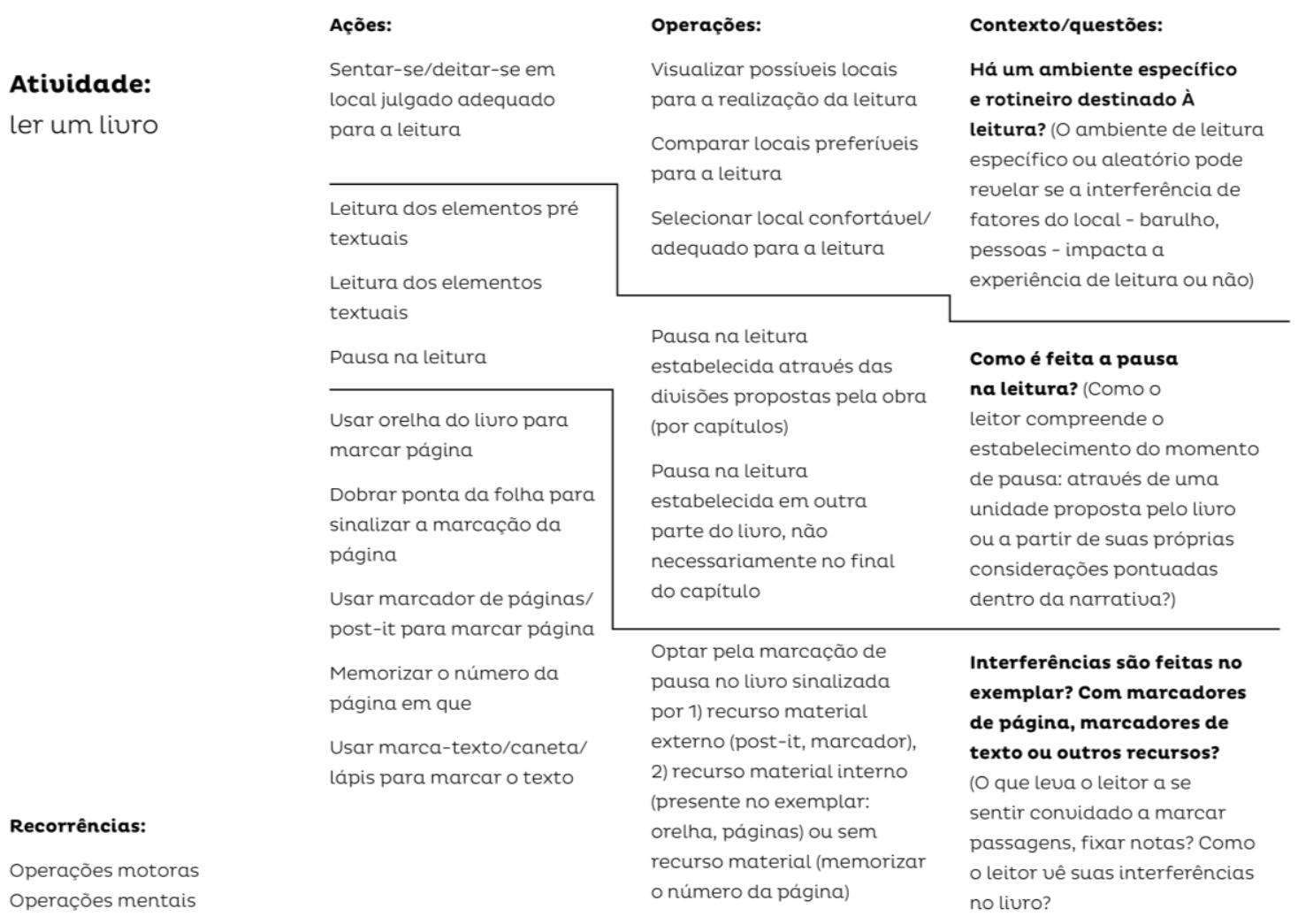

Figura 03: Amostra da divisão da atividade de leitura em ações e operações. Fonte: A autora. 


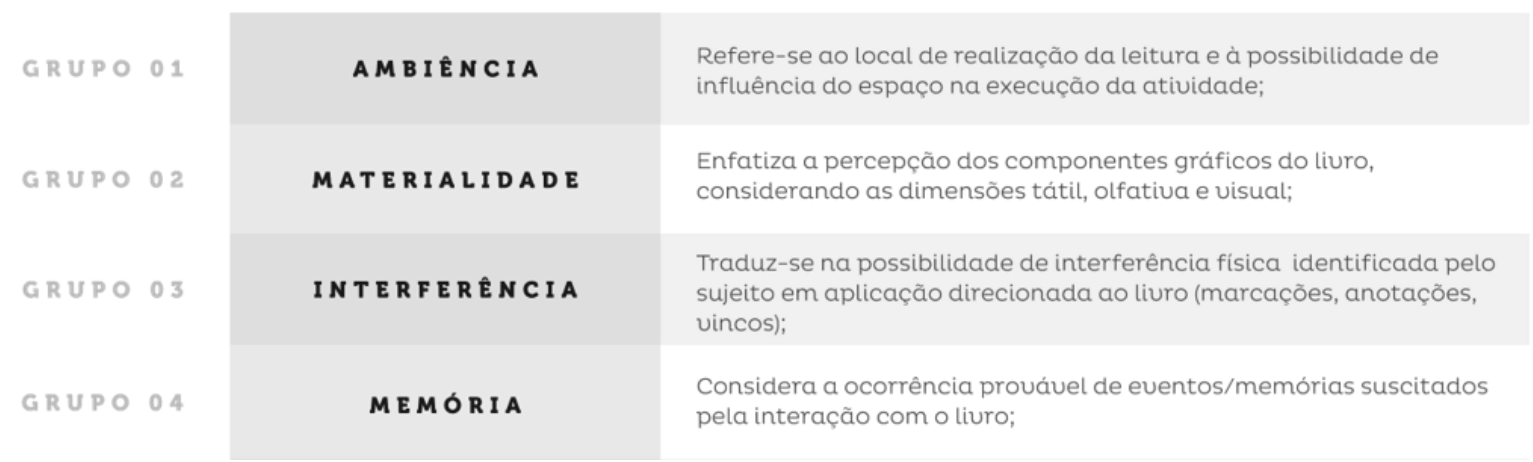

Figura 04: Descrição dos primeiros conjuntos levantados a partir do desdobramento da atividade de leitura na hierarquia da atividade. Fonte: A autora.

Ressalta-se que as ações e operações descritas hierarquicamente pressupõem uma situação ideal para a ocorrência da atividade, não necessariamente correspondendo à ocorrência real da leitura. Contudo, através da sistematização obtida por intermédio do conceito, encontrou-se um recurso para a demarcação de parâmetros que propiciam a avaliação dos sujeitos elencados para a pesquisa.

As questões resultantes também foram relacionadas aos elementos constituintes do diagrama de $2^{\underline{a}}$ geração de Engeström (1987): sujeito, instrumento, objetivo, regras, comunidade e divisão do trabalho, na intenção de evidenciar a mediação entre sujeito e objeto dentro das relações permeadas pelo contexto do leitor:

\begin{tabular}{|c|c|c|}
\hline A M B I Ê NCIA & $\begin{array}{l}\text { Há um ambiente específico e rotineiro destinado à leitura? } \\
\text { (O ambiente de leitura especifico ou aleatório pode demonstrar se fatores do local - } \\
\text { barulho, pessoas - impactam a experiência de leitura) } \\
\text { Como o liuro é guardado? } \\
\text { (Relacionada ao ambiente e estima que o leitor atribui ao liuro) }\end{array}$ & $\begin{array}{l}\text { SUJEITO } \\
\text { COMUNIDADE } \\
\text { REGRAS }\end{array}$ \\
\hline INTERFER Ê NCIA & $\begin{array}{l}\text { Interferências são feitas no exemplar? } \\
\text { Com marcadores de página, marcadores de texto ou outros recursos? } \\
\text { (O que leva o leitor a se sentir convidado a marcar passagens, fixar notas e } \\
\text { o significado que isso pode assumir) } \\
\text { Certas marcas tornam o liuro mais "gostável" pelo leitor? } \\
\text { (Defeitos, inferterências: como podem ser ressignificados pelo leitor) }\end{array}$ & $\begin{array}{l}\text { SUJEITO } \\
\text { ARTEFATO } \\
\text { OBJETIVO }\end{array}$ \\
\hline MEMÓRIA & $\begin{array}{l}\text { O liuro pode lembrar algum momento vivido? } \\
\text { (Identificar contextos associados pelo leitor ao liuro) }\end{array}$ & $\begin{array}{l}\text { SUJEITO } \\
\text { ARTEFATO } \\
\text { OBJETIVO } \\
\text { COMUNIDADE } \\
\text { DIVISÃODOTRABALHO }\end{array}$ \\
\hline MATERIALIDADE & $\begin{array}{l}\text { Como um liuro pode ser agradável aos olhos do leitor? } \\
\text { (Compreender como o leitor percebe os aspectos formais do liuro eldentificar se as } \\
\text { dimensões textual e material são enxergadas como igualmente releuantes) } \\
\text { Como a leitura é feita? Por capitulos? } \\
\text { (Compreender como leitor entende divisões e momentos de pausa dentro do contex- } \\
\text { to da narratiua) }\end{array}$ & $\begin{array}{l}\text { SUJEITO } \\
\text { ARTEFATO }\end{array}$ \\
\hline
\end{tabular}

Figura 05: Questões destinadas à entrevista.

Fonte: A autora.

Com as questões direcionadas ao roteiro da entrevista já circunscritas, coordenou-se um estudo experimental piloto. Os dois sujeitos avaliadores dessa etapa integram o Grupo de Estudos em 
Design Editorial, da Universidade Federal do Cariri (UFCA). A seleção dos indivíduos decorre do contato prévio da autora com a instituição de ensino e com o grupo de estudos, bem como pelo alinhamento entre conteúdos abordados no grupo e a proposta da pesquisa, pontos que se mostraram oportunos para a viabilização do trabalho. Dada a formação dos respondentes, considerase a análise como produzida a partir de um olhar especialista. As entrevistas foram realizadas por videoconferência e gravadas através da plataforma Google Meet, com duração média de $1 \mathrm{~h}$, posteriormente transcritas.

\begin{tabular}{cccc} 
SUJEITOS & GENERO & ESCOLARIDADE \\
Sujeito 01 & 21 anos & Feminino & $\begin{array}{c}\text { Ensino superior incompleto } \\
\text { (curso: Design de Produto) }\end{array}$ \\
\hline Sujeito 02 & 24 anos & Masculino & $\begin{array}{c}\text { Ensino superior incompleto } \\
\text { (curso: Design de Produto) }\end{array}$
\end{tabular}

Figura 06: Perfil dos sujeitos entrevistados na primeira etapa da pesquisa. Fonte: A autora.

Com as observações realizadas a partir do estudo piloto, as questões direcionadas à entrevista receberam atualizações 1 ) em relação ao enunciado, de modo a alcançar um direcionamento que não favorecesse respostas pautadas na dicotomia sim x não, ampliando as possibilidades de reflexão para os depoentes a partir do estímulo gerado pela pergunta e 2) delimitação de uma pergunta primária - obtida a partir dos grupos temáticos delimitados em torno das ações e operações - e perguntas secundárias, de modo a construir etapas para favorecer a chegada da fala do sujeito ao interesse pontuado pela pesquisa. Também se reorganizou o desdobramento da atividade de leitura, descrito, em sua fase inicial, na figura 03 e, a partir disso, encontrou-se a possibilidade de formação de um novo conjunto temático para alocação das perguntas, relacionado à frequência e familiaridade com a leitura. Os temas e as perguntas reformuladas apresentam-se da seguinte maneira:

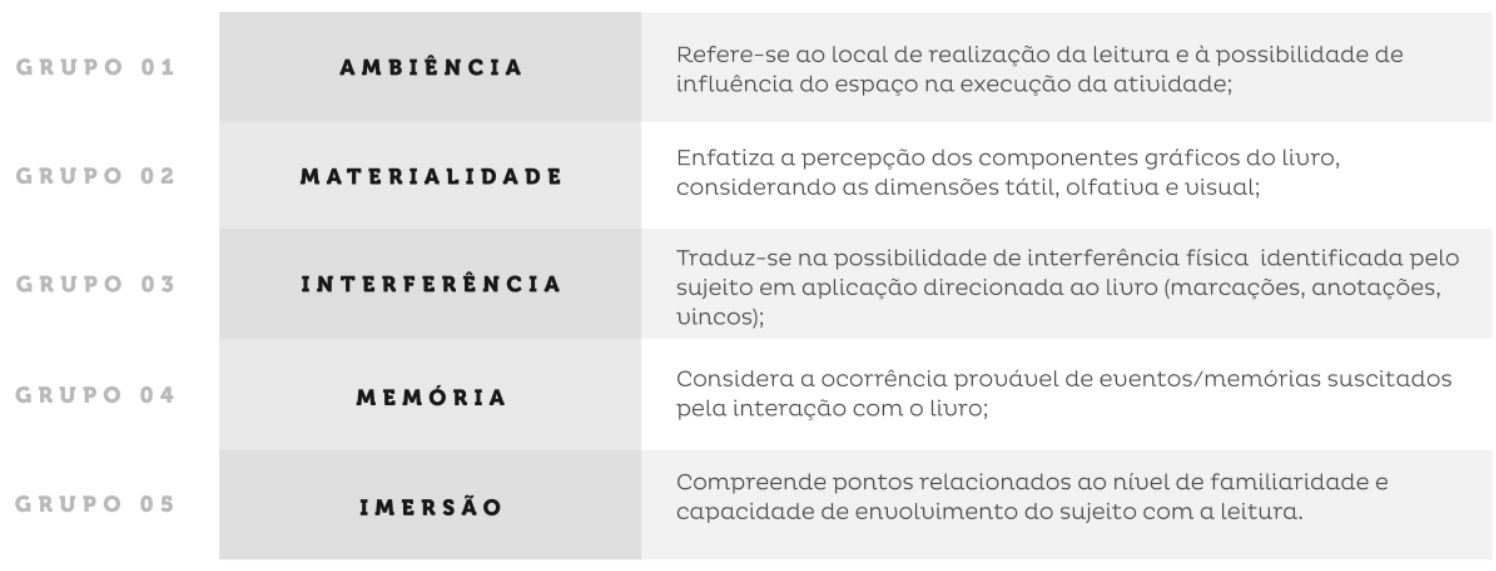

Figura 07: Descrição dos conjuntos temáticos atualizados. Fonte: A autora. 


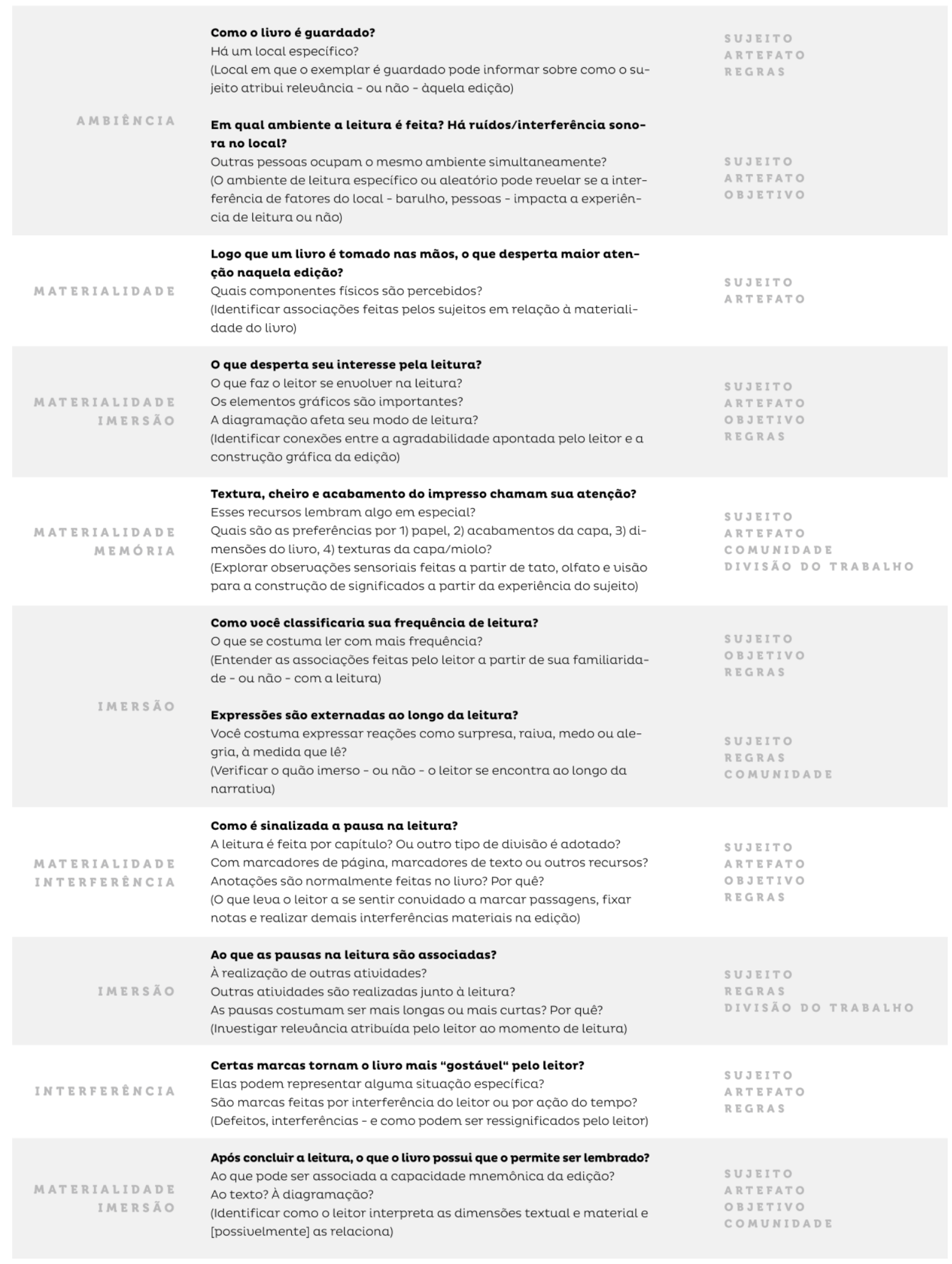

Figura 08: Questões atualizadas para a entrevista. Fonte: A autora. 
O segundo grupo de sujeitos avaliadores é constituído por participantes do clube de leitura do curso de Biblioteconomia da UFCA, o PET Biblio Club. Por incluir a participação de estudantes oriundos de diferentes graduações, o público se constitui como não especialista. Chegou-se ao grupo através da busca, dentro da instituição de ensino, de inciativas que contemplassem a atividade de leitura e o público leitor. O contato com os depoentes ocorreu mediante intermédio e autorização da coordenação do clube, que disponibilizou uma lista dos estudantes interessados em participar da pesquisa, convidados, através de e-mail, para a entrevista realizada no Google Meet, registrada em áudio e posteriormente transcrita. Para essa etapa, ouviu-se 03 sujeitos, com duração média de 20 minutos por diálogo.

$\begin{array}{cccccc}\text { SUJEITOS } & \text { GENERO } & \text { ESCOLARIDADE } & \text { LOCALIDADE } \\ \text { Sujeito } 03 & 20 \text { anos } & \text { Feminino } & \begin{array}{c}\text { Ensino superior incompleto } \\ \text { (curso: Engenharia Civil) }\end{array} & \text { Juazeiro do Norte- CE } \\ \text { Sujeito } 04 & 20 \text { anos } & \text { Masculino } & \begin{array}{c}\text { Ensino superior incompleto } \\ \text { (curso: Engenharia Civil) }\end{array} & \text { Juazeirodo Norte-CE } \\ \text { Sujeito } 05 & 20 \text { anos } & \text { Masculino } & \begin{array}{c}\text { Ensino superior incompleto } \\ \text { (curso: Engenharia Civil) }\end{array} & \text { Juazeiro do Norte-CE }\end{array}$

Figura 09: Perfil dos sujeitos entrevistados na segunda etapa da pesquisa. Fonte: $A$ autora.

\section{Considerações sobre as informações levantadas}

O levantamento de informações facilitado pelas questões possibilitou a coleta de pontos relevantes na experiência de leitura a partir das perspectivas de cada sujeito. Aqui, apresenta-se um recorte das particularidades observadas nas respostas, relacionando o perfil dos sujeitos e aspectos pontuados nas perguntas realizadas. No segundo tópico da presente seção, tem-se os significados particulares identificados a partir das falas dos depoentes.

A frequência de leitura descrita pelos sujeitos não-especialistas é mais alta em relação a obras de literatura acadêmica, ao passo que livros de literatura são mais lidos pelos indivíduos especialistas. 0 tempo disponível impacta na regularidade do ato de ler: todos os entrevistados relatam queda no ritmo de leitura ocasionado pela quantidade de atividades acadêmicas que, em certos casos, ainda é conciliada com jornadas de trabalho. Ainda assim, ler ocupa um nível de importância cotidiana para os depoentes; apesar da queixa em relação à periodicidade dela, todos afirmam praticar a leitura. $\mathrm{O}$ PET Biblio Club é apontado, pelo sujeito 03 , como um incentivo à pratica. Na fala do sujeito 05 , observou-se que a redução do período disponível para a leitura condiciona o tipo de obra lida por ele, que opta por livros com capítulos mais curtos, favorecendo a conclusão da leitura daquele bloco de texto em um intervalo de tempo reduzido. 
Apesar do intuito da pesquisa se direcionar ao livro impresso, ponto sinalizado aos sujeitos no início das entrevistas, o livro digital foi trazido à tona nas falas dos depoentes. O formato eletrônico surge para os indivíduos não como preferido, mas como uma opção mais viável do que o impresso, devido a seu baixo custo ou mesmo gratuidade, assim como pela dificuldade, devido à pandemia, de acesso a bibliotecas que disponibilizam seu acervo físico gratuitamente. Encontra-se uma relação entre o perfil econômico dos participantes e o formato de livro que leem, não ocasionada pela predileção, mas pela acessibilidade favorecida pelos e-books. O fator financeiro também é identificado, na fala do sujeito 01 , como influente nas interferências físicas que o leitor visualiza como possíveis ou não de efetuar na materialidade do livro: o indivíduo prefere não realizar anotações ou marcações devido ao preço da edição.

Há recorrência de pontos relacionados ao projeto gráfico entre os indivíduos especialistas e maior importância atribuída à textualidade entre os não-especialistas. O sujeito 05 constitui uma exceção e apresenta comentários sobre a materialidade do livro ao longo de sua entrevista. A observação mais atenta à diagramação, para ele, decorre de experiências negativas com livros, gerando a necessidade de contato com um impresso de maior cuidado em seu acabamento. 0 sujeito 04 associa a redução do interesse voltado à materialidade, quando comparado à textualidade, também em função de experiências negativas: descreve momentos em que associou uma avaliação positiva da narrativa contida pela edição devido aos atributos sensoriais encerrados pelo livro (cheiro, textura), mas, após iniciada a leitura, afirmou não ter gosto pelo texto.

Acrescenta-se, aqui, a não intencionalidade de restrição a uma graduação específica dos sujeitos não-especialistas. Através de comentários feitos pelos depoentes em questão, observou-se que o interesse na participação da pesquisa surgiu de um grupo de estudantes do curso, com afinidade entre si e do mesmo período. Assim, com a iniciativa do conjunto, os estudantes sentiram-se mais confortáveis em cooperar com o trabalho.

Abaixo, encontram-se descritos os procedimentos envolvidos no tratamento das informações coletadas para a identificação de significados particulares aos leitores dentro da atividade de leitura.

\section{Tratamento das informações}

A sistematização das informações levantadas a partir das falas dos sujeitos ocorre em quatro etapas: 1) reunião das respostas obtidas nas entrevistas através dos grupos temáticos sugestionados pelas questões; 2 ) identificação de termos recorrentes presentes nas transcrições (para auxiliar a visualização dessas repetições, utilizou-se uma nuvem de palavras, produzida com o software NVivo, filtrada pelos 30 termos mais recorrentes nas falas); 3) associação entre a repetição de vocábulos e 
seu contexto de origem aos elementos do diagrama de 2 a geração e 4) identificação dos significados indicados pelos sujeitos a partir das considerações obtidas nas fases anteriores. A organização aqui aplicada adapta procedimentos de categorização presentes em estudo de Baptista (2019), no intuito de facilitar a discussão dos resultados. Através do tratamento das informações, conseguiu-se capturar determinados significados identificados na atividade de leitura através das falas dos depoentes, com trechos destacados abaixo:

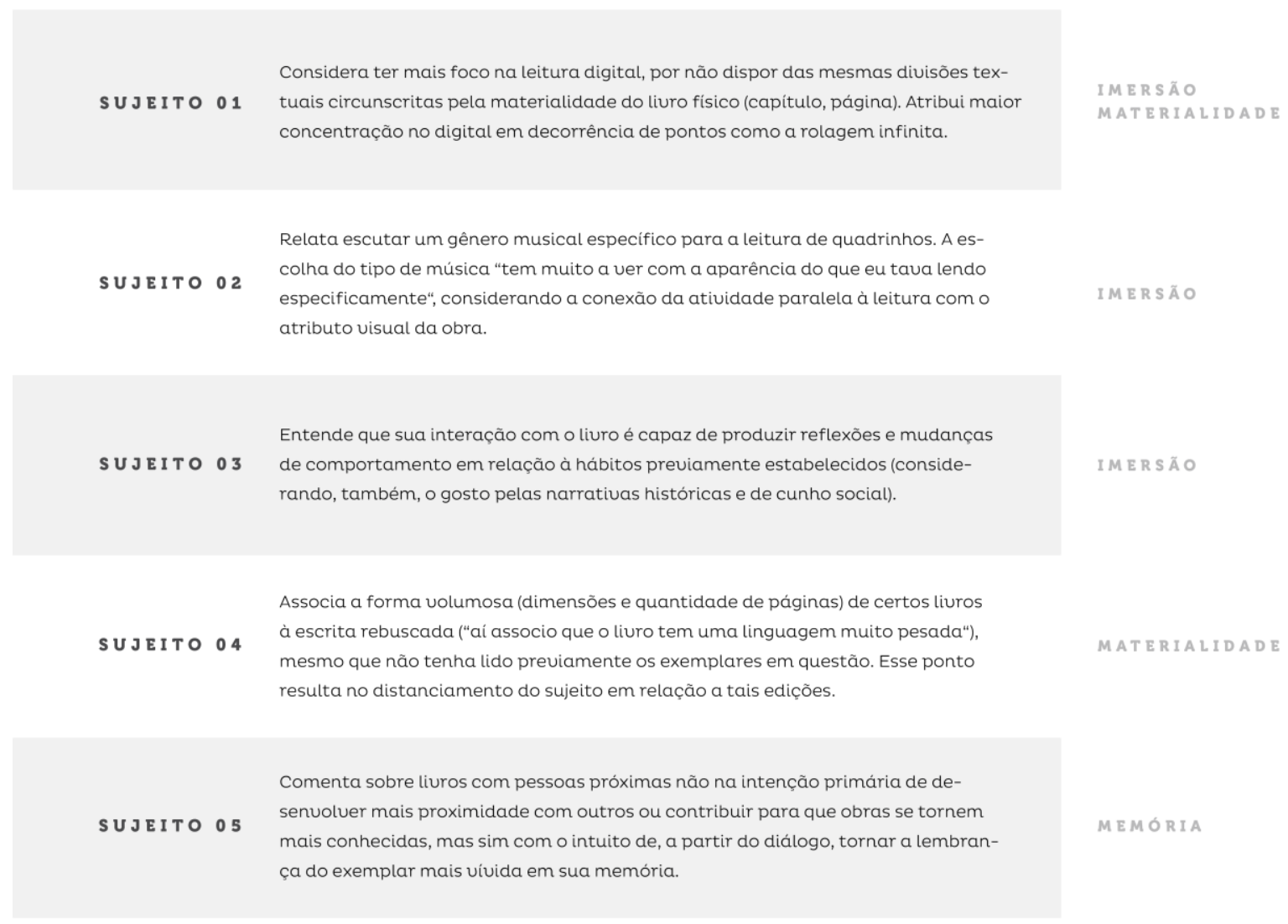

Figura 10: Trechos com alguns dos significados trazidos pelas falas dos sujeitos. Fonte: A autora.

Observa-se a relação entre o motivo da atividade e o significado atribuído pelo sujeito às ações compreendidas no processo de leitura, que passam a adquirir, para cada um deles, uma determinada conotação. Certas particularidades também puderam ser verificadas ao longo das falas dos sujeitos, como descrições mais objetivas sobre a interação com o livro, maior uso de verbos no passado, respostas mais curtas feitas por um sujeito que se descreve como mais retraído, mais abertura na menção de aspectos subjetivos e mesmo curiosidade sobre o intuito da pesquisa. Tais questões também fazem parte do universo do leitor, traduzem parte de sua experiência de leitura e fornecem embasamento para a análise da percepção dos sujeitos. 
A ideia de construção de significados aqui presente dialoga com as considerações de Gruszynski (2015), à medida que, na presença do impresso, para além das palavras, a leitura também contempla aspectos como o formato do artefato que as contém e seu peso, tamanho e textura, que podem informar e sensibilizar o leitor diante do livro que tem em mãos. Há uma rede simbólica que relaciona elementos decorrentes da presença palpável do artefato e a maneira pela qual são percebidos junto ao elemento verbal contido pelo impresso, trazendo uma expectativa do leitor ao texto que será lido, ponto exemplificado no trecho citado pelo sujeito 04, presente na figura 10. Nessa perspectiva de leitura que expande o texto verbal, Fischer (2006) também pontua sobre a produção de significados a partir do ato de ler, compreendendo-a como um processamento de informações a partir de uma ótica pessoal; visualiza-se, sente-se emoções, inferências e referências cruzadas são feitas. O texto não é lido apenas verbalmente; há uma construção de significado contextual direcionado a ele.

Como já citado, os e-books ganharam espaço nas falas dos depoentes, ainda que a construção das questões direcionadas aos sujeitos tenham partido de considerações sobre o volume impresso. Dentre os pontos citados sobre o livro digital, destaca-se a fala do sujeito 01 , representada na figura 10. Conforme pesquisa de Campello e Baptista (2016), as possibilidades atribuídas a uma maior compreensão percebida no assunto trazido pelo texto presente no meio eletrônico podem ser exemplificadas pelo tipo de visualização do texto nesse tipo de suporte, que ocupa boa parte do espaço em tela, ou pelo avanço das páginas feito através da rolagem do conteúdo. Esses pontos podem favorecer um entendimento dos recursos que seriam possíveis favorecedores de conforto na leitura digital. Dada a recorrência de menções ao livro eletrônico, pontua-se sobre a possibilidade de um desdobramento da investigação abordando, também, as publicações digitais e suas particularidades.

Dada a extensão do trabalho, aqui limita-se a citar tais observações e desdobramentos passíveis de investigação.

\section{Considerações finais}

Com a pesquisa, buscou-se produzir um recurso facilitador da identificação de pormenores dentro da experiência de leitura, relacionando os pontos observados a partir da transcrição das falas com os elementos do Sistema de Atividade para identificação de significados pertinentes aos sujeitos. Por intermédio dessa ferramenta, foi possível identificar o ponto de interesse do trabalho, mas ainda se encontra a necessidade de realizar mais testes para refino das questões. Para tal, busca-se dar 
continuidade ao estudo, entrevistando mais grupos de sujeitos na intenção de verificar a efetividade das questões.

O uso do software NVivo, ao mesmo tempo que se mostrou conveniente para a produção das nuvens de palavras, também demandou uma série de ajustes em função da aparição dos termos, como a filtragem de conectivos entre as frases ou a remoção de palavras que poderiam gerar interferência na interpretação dos vocábulos recorrentes. Também se observou que a formação das nuvens de palavras ocorre a partir da recorrência de termos isolados, mas não de expressões formadas por mais de uma palavra (como "marcador de páginas" ou "capa dura"). Levando em conta a limitação que esse ponto pode ocasionar no tratamento das informações levantadas, considera-se a busca por outras opções de softwares direcionados à análise de dados, na intenção de proporcionar a visualização dos termos frequentes de forma mais próxima ao contexto de origem na fala do sujeito entrevistado.

Por fim, pontua-se que o aporte teórico da teoria da atividade mostrou-se como propício não somente para a construção da ferramenta para coleta de informações, mas também na sistematização das considerações levantadas, especialmente na compreensão dos elementos do contexto relacionado à atividade mediada do indivíduo.

\section{Referências:}

BAPTISTA, T. A. A. de A. A [TRANS]FORMAÇÃO DOS ARTEFATOS: um estudo sobre a contribuição dos aspectos históricos da Teoria da Atividade para o Design. 2019. Tese [Doutorado em Design] Departamento de Design, Universidade Federal de Pernambuco, Recife.

CAMPELLO, S. B. Aprendizagem mediada por computador. In: SPINILLO, C.; BENDITO, P.; PADOVANI $S$. (Ed.). Selected readings on information design: communication, technology, history and education. Curitiba: Sociedade Brasileira de Design da Informação, 2009, p. 189 - 200.

CAMPELLO, S. R. B. B.; BAPTISTA, T. A. A. de A. Design centrado na atividade: estudo sobre artefatos impressos e digitais móveis. In: Congresso Brasileiro de Pesquisa e Desenvolvimento em Design, 12, 2016, Belo Horizonte. Anais.. São Paulo: Blucher, 2016, Blucher Design Proceedings, p. 2466-2477.

ENGESTRÖM, Y. Activity theory and individual and social transformation. In: ENGESTRÖM, Y; MIETTINEN, R; PUNAMÄKI, R. (ed.). Perspectives in Activity Theory. Cambridge: Cambridge University Press, 1999, p. 19-38.

ENGESTRÖM, Y. Learning by expanding: an activity-theoretical approach to developmental research. 1987. Tese (doutorado). University of Helsinki, Helsinki.

FISCHER, S. R. História da Leitura. São Paulo: Editora UNESP, 2006.

GRUSZYNSKI, A. C. Design editorial e publicação multiplataforma. Intexto, Porto Alegre, n. 34, p. 571$588,2015$. 
LEONTIEV, A. N. Activity, Consciousness, and Personality. New Jersey: Prentice-Hall, 1978.

. The Problem of Activity in Psychology. In: Wertsch, J.V. (org). The Concept of activity in Soviet psychology. New York: M. E.Sharpe, 1981, p. 37 - 71.

Uma contribuição à teoria do desenvolvimento da psique infantil. In: CIPOLLANETO, J. et. al. Linguagem, desenvolvimento e aprendizagem. 11ª edição. São Paulo: Ícone, 2010, p. $59-83$.

REGO, T. S. Vygostky: uma perspectiva teórico-cultural da educação. Petrópolis: Vozes, 1995.

VYGOTSKI, L.S. A formação social da mente. São Paulo: Martins Fontes, 1992. 